\title{
ВЛИЯНИЕ КАПИТАЛОВЛОЖЕНИЙ НА РАЗВИТИЕ ТУРИЗМА В ЭКОНОМИЧЕСКИ СРЕДНЕРАЗВИТЫХ СТРАНАХ
}

\section{INFLUENCE OF CAPITAL INVESTMENT ON THE DEVELOPMENT OF TOURISM IN ECONOMICALLY MEDIUM-DEVELOPED COUNTRIES}

\section{E. Kutyashova}

O. Skobeleva

Summary: The influence of investment on the growth rate of the contribution of tourism to the gross domestic product of economically average developed countries is considered. The countries were grouped according to the share of tourism in GDP and the level of economic development. The groups of countries with high, medium and low growth rates of the contribution of tourism to GDP are highlighted. Conclusions are made about the role of capital investments in the development of tourism in economically middle-developed countries. An assessment of the effectiveness of investment policy in the field of tourism is given.

Keywords: the contribution of tourism to the gross domestic product, capital investments, economically medium-developed countries, efficiency, investment strategy.
B настоящее время мировой валовой внутренний продукт (ВВП) на 10 \% формируется за счет туризма и связанных с ним услуг. Сектор туризма отвечает за создание каждого четвертого из новых рабочих мест в мире. В 2019 году Всемирная туристическая организация (ЮНВТО) зарегистрировала 1,5 миллиарда международных туристических поездок. Туризм является одним из самых динамично развивающихся секторов экономики, опережающих темпы роста глобальной экономики.

Туризм развивается под воздействием целого ряда факторов:

- политико-правовых, связанных с определением общей концепции государством по отношению к развитию туризма и принятию соответствующих нормативно-правовых актов, регулирующих его развитие;

- безопасности путешествий, связанных с сохранением здоровья туристов;

- экономических факторов, обеспечивающих макроэкономическую стабильность, развитие туристической инфраструктуры;

- культурных факторов;

- социально-демографических факторов, связанных с ростом численности и изменением социаль-
Кутяшова Елена Васильевна

К.э.н., доцент, ФГБОУ ВО «Удмуртский государственный университет», Ижевск

9128504681@mail.ru

Скобелева Ольга Александровна

К.э.Н., доцент, ФГБОУ ВО «Удмуртский государственный университет», Ижевск

Аннотация: Рассмотрено влияние капиталовложений на темпы роста вклада туризма в валовой внутренний продукт экономически среднеразвитых стран. Произведена группировка стран по доле туризма в ВВП и уровню экономического развития. Выделены группы стран с высоким, средним и низким темпом роста вклада туризма в ВВП. Сделаны выводы о роли капиталовложений в развитии туризма экономически среднеразвитых стран. Дана оценка эффективности инвестиционной политики в сфере туризма.

Ключевые слова: вклад туризма в валовой внутренний продукт, капиталовложения, экономически среднеразвитые страны, эффективность, инвестиционная стратегия.

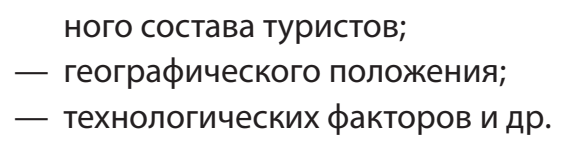

Среди экономических факторов мощнейшим рычагом развития туризма являются капиталовложения. В связи с этим, актуальной представляется оценка влияния капиталовложений на общий вклад туризма в ВВП государства, что позволит сделать выводы об эффективности проводимой инвестиционной политики в сфере туризма. Гипотезой проведенного исследования является наличие связи между темпами роста общего вклада туризма в ВВП страны и темпами роста капиталовложений в туризм. Целью данного исследования является оценка эффективности инвестиционной стратегии экономически среднеразвитых стран в сфере туризма.

Для анализа темпов роста капиталовложений и темпов роста вклада туризма в ВВП проведем группировку стран по уровню развития и значимости туризма в формировании ВВП. Для этого воспользуемся трехступенчатой шкалой, разработанной на основе рекомендаций Всемирного совета по путешествиям и туризму Всемирной туристической организации (ВТО) [1]. 
В первую группу входят страᄀны, в которых доля поступлений от туризма в ВВП не превышает 5\%; во вторую группу - страны со значениями от 5 до 25\%; в третью группу - страны с показателем более 25\%.

Группой Всемирного Банка (ВБ) была разработана классификация стран по уровню экономического развития [2]. По показателю валового национального дохода на душу населения все государства и территории делятся на следующие группы (группировка дана в классификации 2018 г., пороговые значения ежегодно меняются):

- экономически высокоразвитые страны - с высоким уровнем дохода на душу населения от 12,616 тыс. долл. и выше;

- экономически среднеразвитые страны - со средним уровнем дохода на душу населения от 1,036 до 12,615 тыс. долл.;

- экономически низко развитые страны - с низким уровнем дохода на душу населения от 1,035 тыс. долл. и ниже.

Используя классификации, предложенные ВТО и ВБ произведем разбивку стран на шесть групп (таблица 1).

Наиболее многочисленными являются группа экономически среднеразвитых стран и экономически высокоразвитых стран с долей туризма в ВВП от 5 до $25 \%$.
Для анализа за период с 2010 по 2018 год были рассчитаны средние темпы роста общего вклада туризма в ВВП экономически среднеразвитых стран или территорий и средний темп роста капиталовложений в сферу туризма. Данные по общему вкладу туризма в ВВП и объему капиталовложений в туризм использованы в постоянных ценах 2011г. [3]. Для расчета среднего коэффициента роста использована средняя геометрическая. Средняя геометрическая в данном случае является предпочтительнее, так как дает наиболее правильный по содержанию результат, когда требуется найти такое значение экономической величины, которое было бы качественно равноудалено как от ее максимального, так и от минимального значения. Внутри группы выделены страны с высокими (свыше 8 \%), средними (4-7\%), низкими (3\% и менее) темпами роста вклада туризма в ВВП.

Рассмотрим среднеразвитые страны с высокими темпами роста общего вклада туризма в ВВП и долей туризма в ВВП от 5 до 25 \% (рисунок 1).

Наиболее высокие средние темпы роста вклада туризма в ВВП демонстрируют такие страны, как Мьянма 22\%, Филиппины 16\%, Кот-д'Ивуар 15\%, Шри-Ланка, Азербайджан - 13\%, Ирак 12\%, Китай 11\%. Самый высокий средний темп роста вклада в ВВП демонстрирует Мьянма, что связана с переходом к открытой экономике, экзотичностью и доступностью туристического отдыха.

Таблица 1

Группировка стран по доле туризма в ВВП и уровню экономического развития в 2018 г.

\begin{tabular}{|c|c|c|c|}
\hline \multirow{2}{*}{$\begin{array}{c}\text { Уровень экономиче- } \\
\text { ского развития стран } \\
\text { и территорий }\end{array}$} & \multicolumn{3}{|c|}{ Доля туризма в ВВП } \\
\hline & Д0 $5 \%$ & $5-25 \%$ & Свыше $25 \%$ \\
\hline $\begin{array}{l}\text { экономически низко } \\
\text { развитые страны }\end{array}$ & $\begin{array}{l}\text { Сьерра-Леоне, Нигер, } \\
\text { Бурунди, Чад, Буркина- } \\
\text { Фасо, ДР Конго }\end{array}$ & $\begin{array}{l}\text { Гамбия, Мадагаскар, Руанда, Танзания, Эфиопия, Мали, Того, Мозамбик, } \\
\text { Таджикистан, Непал, Гаити, Уганда, ЦАР, Йемен, Бенин, Гвинея }\end{array}$ & \\
\hline $\begin{array}{l}\text { экономически } \\
\text { среднеразвитые } \\
\text { страны }\end{array}$ & $\begin{array}{l}\text { Россия, Судан, Бан- } \\
\text { гладеш, Парагвай, } \\
\text { Киргизия, Ангола, } \\
\text { Суринам, Узбекистан, } \\
\text { Ливия, Габон, Молдова, } \\
\text { Папуа-Новая Гвинея }\end{array}$ & $\begin{array}{l}\text { Филиппины, Черногория, Тонга, Сальвадор, Китай, Намибия, Тунис, } \\
\text { Турция, Египет, Шри-Ланка, Кот-д'Ивуар, Индия, Вьетнам, Македония, } \\
\text { Пакистан, Беларусь, Индонезия, Эквадор, Доминиканская Республика, } \\
\text { Таиланд, Иордания, Монголия, Болгария, Босния и Герцеговина, Лесото, } \\
\text { Сенегал, Перу, Кения, Армения, Ботсвана, Коста-Рика, Камерун, Сербия, } \\
\text { Мьянма, Колумбия, Гана, Гайана, Ливан, Марокко, Кирибати, Мексика, } \\
\text { Гондурас, Малайзия, Азербайджан, Соломоновы о-ва, Лаос, Никарагуа, } \\
\text { Аргентина, Коморские острова, ЮАР, Ирак, Бразилия, Гватемала, Зам- } \\
\text { бия, Боливия, Алжир, Зимбабве, Казахстан, Украина, Конго, Румыния, } \\
\text { Нигерия, }\end{array}$ & $\begin{array}{l}\text { Мальдивы, Кабо Верде, } \\
\text { Белиз, Сент Люсия, } \\
\text { Фиджи, Ямайка, Грузия, } \\
\text { Доминика, Камбоджа, } \\
\text { Албания, }\end{array}$ \\
\hline $\begin{array}{l}\text { экономически высо- } \\
\text { коразвитые страны }\end{array}$ & $\begin{array}{l}\text { Литва, Польша, Южная } \\
\text { Корея, }\end{array}$ & $\begin{array}{l}\text { Хорватия, Кипр, Маврикий, Греция, Португалия, Гонконг, Словения, } \\
\text { Новая Зеландия, Франция, Австрия, Канада, Япония, Словакия, Люк- } \\
\text { сембург, Венгрия, Чехия, Латвия, Ирландия, Кувейт, Уругвай, Испания, } \\
\text { Панама, Бахрейн, Италия, ОАЭ, Великобритания, Мальта, Австралия, } \\
\text { Чили, Сингапур, Швеция, Катар, Оман, Норвегия, Саудовская Аравия, } \\
\text { Финляндия, Германия, Швейцария, Дания, США, Тринидад и Тобаго, } \\
\text { Пуэрто-Рико, Бруней, Израиль, Бельгия, Нидерланды. }\end{array}$ & $\begin{array}{l}\text { Макао, Сейшельские } \\
\text { острова, Сент-Китс и Не- } \\
\text { вис, Антигуа Барбуда, }\end{array}$ \\
\hline
\end{tabular}


При этом Китай, Филиппины, Шри-Ланка и Кот-д' Ивуар имеют и наиболее высокие темпы прироста вклада туризма в ВВП [3]. Так, Китай направляет огромные инвестиции в инфраструктуру, необходимую для принятия большого числа иностранных туристов. Новый аэропорт Дасин в Пекине (Beijing Daxing Airport) после открытия в 2019г. стал крупнейшим аэропортом в мире, а открытие нового терминала международного аэропорта Гуанчжоу Байюнь позволило увеличить его пропускную способность до 100 миллионов пассажиров в год [4].

Одной из важнейших характеристик инвестиционной стратегии страны является соотношение темпов экономического роста с объемом инвестиций. Чем больший прирост достигается за счет единицы инвестиций, тем эффективнее инвестиционная стратегия.

Для оценки эффективности инвестиционной стратегии в этой группе стран, рассмотрим соотношение средних темпов роста общего вклада туризма в ВВП и капиталовложений в сферу туризма (таблица 2).

Мы видим, что темпы роста вклада туризма в ВВП по этой группе стран превышают темпы роста капиталовложений в туристическую отрасль (за исключением Азербайджана, Монголии и Камеруна), что свидетельствует об эффективности инвестиционной политики, проводимой в сфере туризма.

В таких странах, как Монголия, Азербайджан и Камерун наблюдаются опережающие темпы роста капиталовложений в туризм по отношению к темпам роста общего вклада туризма в ВВП. Такое соотношение, на наш взгляд, может в отдельных случаях означать активизацию инвестиционной стратегии страны в сфере туризма. Так, Правительство Монголии объявило туризм одним из приоритетных направлений экономического развития. Принята национальная Программа по развитию туризма на 2016-2025 год, которая делает упор на содействие развитию экологического туризма и создание эффективной сети автомобильных дорог, обеспечивающей высокую мобильность. Правительство Монголии поставило перед собой цель привлекать в страну до 1 млн. иностранных туристов и зарабатывать на туризме до 1 млрд. долл. в год. Таким образом, в перспективе можно ожидать более высокой отдачи от производимых капи-

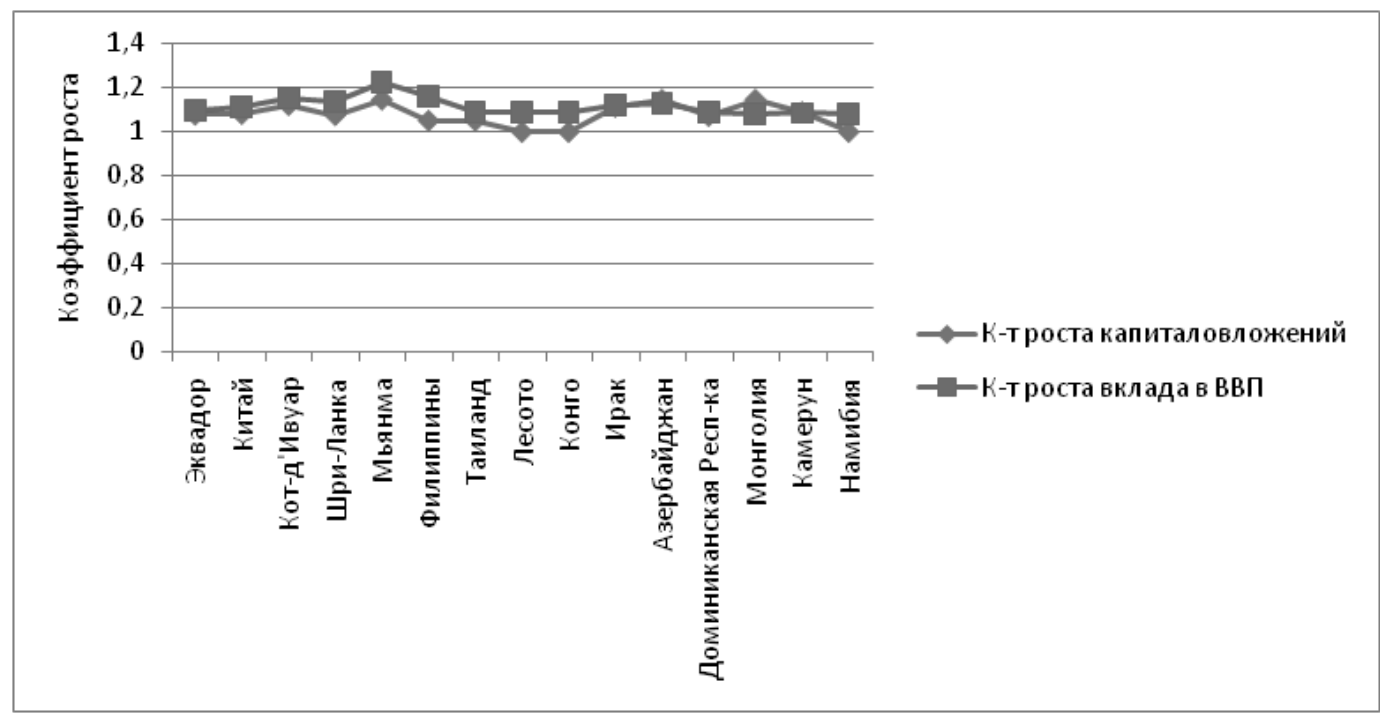

Рис. 1. Средние коэффициенты роста вклада туризма в ВВП и капиталовложений за период 2010-2018 гг. среднеразвитых стран с темпами роста вклада туризма в ВВП 8-22\%

Таблица 2

Эффективность инвестиционной стратегии в сфере туризма в странах с темпами роста вклада туризма в ВВП 8-22\%

\begin{tabular}{|l|l|l|l|l|l|}
\hline Страна & $\begin{array}{l}\text { Коэффициент эффек- } \\
\text { тивности }\end{array}$ & Страна & $\begin{array}{l}\text { Коэффициент эффек- } \\
\text { тивности }\end{array}$ & $\begin{array}{l}\text { Страна } \\
\text { Коэффициент эффек- }\end{array}$ \\
\hline Китай & 1,028 & Эквадор & 1,019 & Доминиканская Респ-ка & 1,013 \\
\hline Кот-д'Ивуар & 1,025 & Таиланд & 1,038 & Намибия & 1,082 \\
\hline Шри-Ланка & 1,056 & Лесото & 1,091 & Азербайджан & 0,986 \\
\hline Мьянма & 1,066 & Конго & 1,091 & Монголия & 0,943 \\
\hline Филиппины & 1,105 & Ирак & 1,008 & Камерун & 0,996 \\
\hline
\end{tabular}


таловложений.

Рассмотрим среднеразвитые страны со средними темпами роста общего вклада туризма в ВВП и долей туризма в ВВП от 5 до $25 \%$ (рисунок 2).

Большая часть стран данной группы также демонстрируют опережающие темпы роста общего вклада туризма в ВВП по отношению к средним темпам роста капиталовложений. Так, опережающие средние темпы роста общего вклада туризма в ВВП имеют Индия, Вьетнам, Македония, Армения, Казахстан, Малайзия, Перу и другие. В таких странах, как Турция, Индонезия, Сербия, Боливия, Никарагуа, Лаос средние темпы роста капиталовложений опережают темпы роста общего вклада туризма в ВВП. В большинстве случаев, это не означает отсутствие эффективной инвестиционной политики, а пожалуй, наоборот говорит о набирающих темпах развития туристической отрасли. Так, в Индонезии сред- ние темпы роста капиталовложений значительно опережают рост вклада туризма в ВВП. Это связано с тем, что Индонезия ускоряет развитие четырех приоритетных туристических направлений по всей стране, чтобы стимулировать туристическую отрасль. Приоритетными направлениями капиталовложений являются храм Боробудур в Магеланге (Центральная Ява); озеро Тоба (Северная Суматра), Лабуан Баджо (Восточная Нуса-Тенггаре) и туристическая зона Мандалика в Ломбоке (Западная Нуса-Тенггара). Строительство международного аэропорта Джокьякарты планируется завершить в 2020 году. Туризм в Боливии также является одним из растущих секторов экономики. Правительством Боливии принята Программа развития туризма, предусматривающая подготовку специалистов в этой области и инвестиции в инфраструктуру.

Совершенно иная картина наблюдается у среднеразвитых стран с низкими средними темпами роста общего

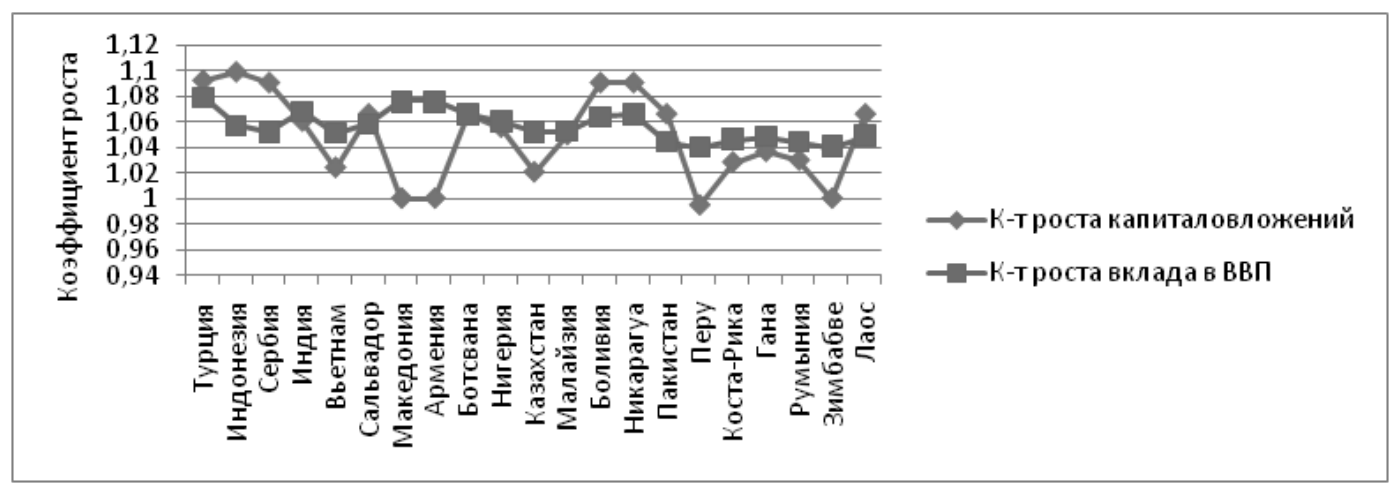

Рис. 2. Средние коэффициенты роста вклада туризма в ВВП и капиталовложений за период 2010-2018 гг. среднеразвитых стран с темпами роста вклада туризма в ВВП 4-7\%

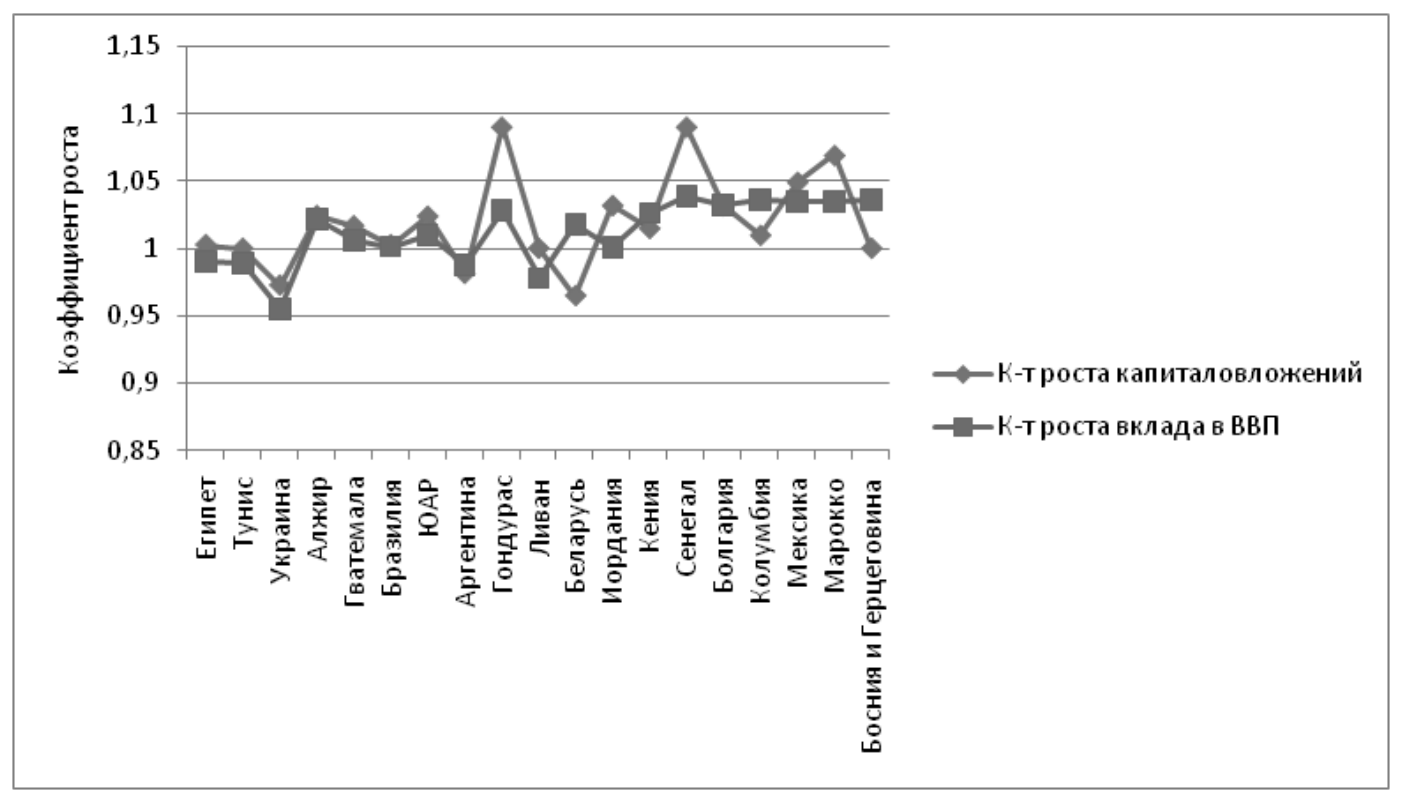

Рис. 3. Средние коэффициенты роста вклада туризма в ВВП и капиталовложений за период 2010-2018 гг. среднеразвитых стран с темпами роста вклада туризма в ВВП 3\% и менее 
Таблица 3

Эффективность инвестиционной стратегии в сфере туризма в странах с темпами роста вклада туризма в ВВП не более $3 \%$

\begin{tabular}{|l|l|l|l|l|l|}
\hline Страна & $\begin{array}{l}\text { Коэффициент эффек- } \\
\text { тивности }\end{array}$ & Срана & $\begin{array}{l}\text { Коэффициент эффек- } \\
\text { тивности }\end{array}$ & $\begin{array}{l}\text { Страна } \\
\text { тивноициент эффек- }\end{array}$ \\
\hline Египет & 0,989 & Аргентина & 1,007 & Болгария & 1,056 \\
\hline Тунис & 0,989 & Гондурас & 0,943 & Колумбия & 1,026 \\
\hline Украина & 0,982 & Ливан & 0,978 & Мексика & 0,986 \\
\hline Алжир & 0,997 & Беларусь & 1,056 & Марокко & 0,968 \\
\hline Гватемала & 0,990 & Иордания & 0,971 & Босния и Герцеговина & 1,056 \\
\hline Бразилия & 0,999 & Кения & 1,011 & & \\
\hline ЮАР & 0,987 & Сенегал & 0,953 & & \\
\hline
\end{tabular}

вклада туризма в ВВП (рисунок 3).

В этой группе в большинстве стран средний коэффициент роста капиталовложений в туризм превышает средний темп роста общего вклада туризма в ВВП страны. Это может означать как отсутствие эффективной инвестиционной политики в развитии туризма, так и формирование активной инвестиционной политики, отдача от которой возможна в перспективе. Также, мы видим, что ряд стран демонстрирует падение средних темпов роста общего вклада туризма в ВВП - Египет, Тунис, Украина, Аргентина, Ливан.

Для оценки эффективности инвестиционной стратегии в этой группе стран, рассмотрим соотношение средних темпов роста общего вклада туризма в ВВП и капиталовложений в сферу туризма (таблица 3).

Мы видим, что средние темпы роста капиталовложений в туристическую отрасль по этой группе стран превышают темпы роста вклада туризма в ВВП, за исключением Болгарии, Колумбии, Аргентины, Кении, Боснии и Герцеговины и Беларуси. Хотя коэффициент эффективности в большинстве стран стремится к единице, это означает низкую эффективность реализуемой инвестиционной стратегии в сфере туризма на сегодняшний день.

В ряде стран - Бразилия, Алжир, Сенегал - это можно объяснить тем, что туризм является молодой, активно развивающейся отраслью экономики. Так, в Сенегале было создано специальное агентство, которому поставлена задача к 2023 году увеличить число туристов до трех миллионов человек и тем самым включить Сенегал в пятерку наиболее посещаемых стран Африканского континента. Зачастую туризм в этих странах развивается в целях диверсификации экономики. Так, Алжир, планирует увеличить размер инвестиций для сектора туризма, преследуя цель привлекать около 3,5 млн. туристов ежегодно, для того чтобы сделать свою экономику менее за- висимой от нефти и газа.

Эффективность проводимой инвестиционной политики в сфере туризма зависит от наличия специально разработанной комплексной государственной стратегии, с поэтапным планом ее реализации. Так, Правительством Болгарии принята Национальная стратегия развития туризма в Болгарии с 2014 по 2030гг. Согласно разработанной государственной стратегии, планируется создать уникальный туристический продукт, который рассчитан на туристов, возраст которых превышает 65 лет. Этот продукт будет совмещать в себе несколько видов туризма: бальнеологический, сельский, культурнопознавательный и экологический. Благодаря созданию такого туристического продукта, Болгария будет являться «благоприятным местом жительства» для людей, возраст которых превышает 50 лет. С 2020 по 2030 гг. национальная реклама будет направлена специально на эту возрастную группу иностранных туристов. Документ определяет на долгосрочный период перспективы развития внутреннего туризма, планирование инвестиций, работу по подготовке персонала в области туризма и другие планы.

Проведенные исследования позволяет нам сделать следующие выводы:

- высокие темпы роста вклада туризма в ВВП экономически среднеразвитых стран с долей туризма в ВВП 5-25 \% обеспечиваются за счет высоких темпов роста капиталовложений в туризм;

- превышение средних темпов роста общего вклада туризма в ВВП над темпами роста капиталовложений в туризм, позволяет сделать вывод, что проводимая инвестиционная политика в сфере туризма является эффективной;

- опережающие средние темпы роста капиталовложений по отношению к темпам роста вклада туризма в ВВП могут означать:

А) низкую эффективность проводимой инвести- 
ционной стратегии в сфере туризма;

Б) туризм не является приоритетным направлением развития страны, капиталовложения осуществляются с целью диверсификации экономики;

В) страна активизировала стратегию развития туризма, реализует комплексную программу развития отрасли, отдача от капиталовложений ожидается в перспективе.

- капиталовложения в туристическую отрасль возрастают, если отдача превышает объем инвестированного капитала и таким образом, сфера туризма становится более привлекательной как для национальных, так и для зарубежных инвестиций.

Таким образом, для эффективного развития туристи- ческой отрасли необходимо стремиться к тому, чтобы темпы экономического роста опережали темпы роста вложенных инвестиций.

Также стоит отметить, что страны с развивающейся экономикой опережают развитые страны как по темпам роста вклада туризма в ВВП, так и по темпам роста капиталовложений в туристическую отрасль [3]. На медленный рост вклада туризма в ВВП в развитых странах безусловно оказывает влияние низкие темпы роста капиталовложений в развитие туристической отрасли. Многие развитые страны не в состоянии модернизировать свою туристическую инфраструктуру также быстро, как это происходит в странах с развивающейся экономикой.

\section{ЛИТЕРАТУРА}

1. Международные рекомендации по статистике туризма официальный сайт Всемирного совета по путешествиям и туризму BTO https://wttc.org/

2. Рейтинг стран мира по уровню валового национального дохода на душу населения https://gtmarket.ru/ratings/gross-national-income-ranking

3. Туризм, общий вклад в ВВП, в постоянных ценах 2011 г. (млрд. долл. (ША) https://knoema.ru/atlas/topics/Туризм/общий-вклад-туризма-в-ВВП

4. Международное исследование UНY: доля туризма в ВВП разных стран. http://collegia.by/info/news/2018/mezhdunarodnoe-issledovanie-uhy-dolyaturizma-v-vvp-raznykh-stran/

( ) Кутяшова Елена Васильевна (9128504681@mail.ru), Скобелева Ольга Александровна

Журнал «Современная наука: актуальные проблемы теории и практики»

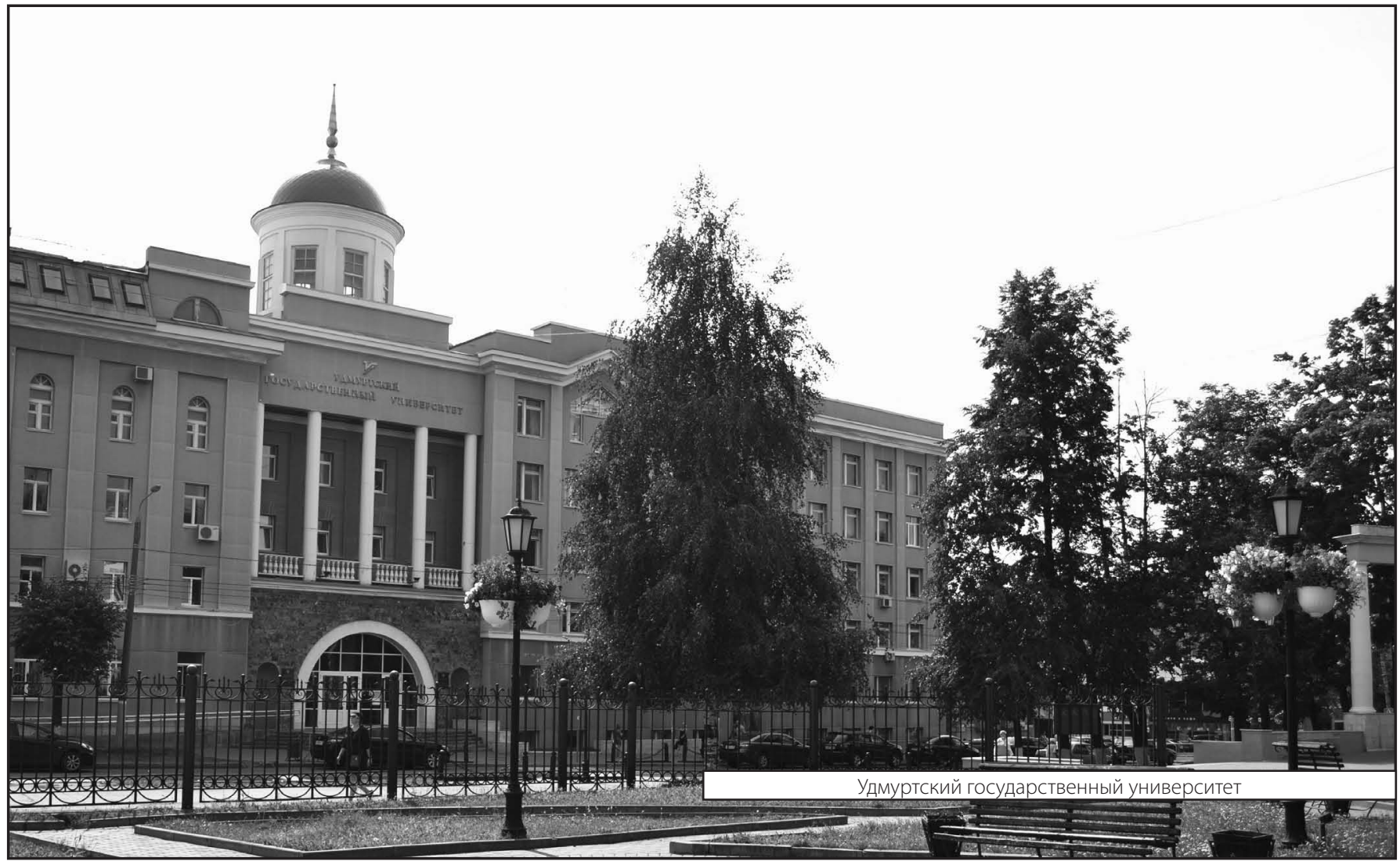

